Gut, 1987, 28, 981-987

\title{
Increased activity of digestive enzymes in ileal enterocytes adapting to proximal small bowel resection
}

\author{
M CHAVES, M W SMITH, AND R C N WILLIAMSON \\ From the Department of Surgery, University of Bristol, Bristol and AFRC, Institute of Animal Physiology, \\ Babraham, Cambridge
}

SUMmaRY The ability of adapting ileal enterocytes to express different digestive enzymes in their brush border membranes was tested in young female Wistar rats $(n=72)$ receiving $60 \%$ proximal small bowel resection. In control rats with intestinal transection both neutral aminopeptidase and $\alpha$-glucosidase activities were shown, by quantitative cytochemistry, to increase during enterocyte migration over the lower part of the villus; thereafter enzyme activities declined or remained approximately constant. Proximal enterectomy increased the amount of $\alpha$-glucosidase but not neutral aminopeptidase activity appearing during early enterocyte development. Thymidine labelled autoradiography showed that the rate of enterocyte migration along the ileal villus nearly doubled after jejunal resection $(19 \cdot 3 v 11 \cdot 1 \mu \mathrm{m} / \mathrm{h})$. Nevertheless, the time taken for both peptidase and saccharidase activities to appear at maximal rates in the brush border membrane was diminished by about five hours. Thus ileal enterocytes adapt to proximal small bowel resection by selective increments in enzyme expression, findings that contradict the previous hypothesis of simple metabolic immaturity.

Intestinal adaptation improves the symptoms of short bowel syndrome in patients surviving massive enterectomy and sometimes thwarts the treatment of morbid obesity by enteric bypass.' Surgical resection is, indeed, one of the strongest stimuli to adaptive growth, loss of the proximal small bowel being compensated for by a prompt and persistent hyperplasia throughout the ileum. ${ }^{2}$ Villi become taller and broader, crypts elongate, and the normally rapid proliferation of enterocytes is further accelerated. ${ }^{13}$ As a result the absorptive surface of the remaining small bowel is greatly enlarged. Thus it is quite consistent to find increased glucose absorption per unit length of small intestine, both in animals and in man. ${ }^{+7}$ Because galactose absorption is unaltered, however, this disappearance of glucose could partly result from increased utilisation by the hyperplastic mucosa.?

Address for correspondence: Professor R C N Williamson, Department of Surgery, Bristol Royal Infirmary, Bristol BS2 \&HW

Received for publication 5 December 1986.
Functional adaptation of the gut might reflect increased numbers of enterocytes or greater capacity of individual cells to digest and absorb nutrients. In rats the small bowel response to partial tissue loss includes decreased uptake of sugars and amino acids in vitro $^{7 x}$ and lower specific activities for several saccharidase and peptidase enzymes. ${ }^{(-9}$ Moreover, enterocytes migrate twice as fast and their lifespan is reduced. ${ }^{311}$ These findings could indicate that the adapting mucosa is lined by cells that are metabolically immature. ${ }^{x}$ Yet previous studies overlook the fact that nutrient absorption is restricted to fully differentiated cells approaching the villus tip, and that this population of enterocytes might change during the hyperplastic response." The recent development of quantitative cytochemistry allows digestive function to be examined along the length of the villus. Using this technique, we find that functional adaptation of the shortened gut is a complex phenomenon that incorporates both hypothetical changes: more cells overall and cells that express certain enzymes at higher activities. 


\section{Methods}

ANIMALS

All experiments were carried out on female Wistar rats weighing $130-170 \mathrm{~g}(\mathrm{n}=72)$ maintained on a standard pelletted diet and given tap water to drink ad libitum.

\section{SURGICAL. PROCEDURE}

A midline incision was made in rats anaesthetised with ether, and the intestine was laid out on warm saline moistened gauze. In 32 rats the proximal $60 \%$ of the small bowel, measured from the ligament of Treitz to the ileocaecal valve, was resected; continuity was re-established by an end-to-end anastomosis. The abdomen was closed and the animals were allowed to recover.

Two control groups of rats were subjected to a similar surgical procedure but with the intestine transected and rejoined in the ileum $(n=20)$ or jejunum $(n=20)$. All operated animals were injected with vitamin $\mathrm{K}(0.25 \mathrm{mg} / \mathrm{kg})$ and were given a sugared salt solution to drink $(0.4 \% \mathrm{NaCl}$ containing $2.5 \%$ glucose) during the first postoperative day. Both test and sham-operated groups of animals were then returned to the standard diet and given tap water to drink for three weeks before being killed for experiment. The numbers of rats surviving for analysis are given in Table 1.

\section{EXPERIMENTAL PROCEDURE}

Rats were killed by cervical dislocation at different times after the intraperitoneal injection of tritiated thymidine $(1 \mu \mathrm{Ci} / \mathrm{g})$, and a $4 \mathrm{~cm}$ long intestinal segment was removed 2 to $6 \mathrm{~cm}$ distal to the anastomosis. This segment was rinsed in phosphate buffered saline and divided into two portions. One portion was fixed immediately in glutaraldehyde sucrose buffer for subsequent measurement of enterocyte migration rate and intestinal structure.

Table 1 Effect of intestinal resection on the structural characteristics of rat distal ileum

\begin{tabular}{lll}
\hline & \multicolumn{2}{l}{ Rat intestinal structure } \\
\cline { 2 - 3 } Tissue & Villus height $(\mu \mathrm{m})$ & Crypt depth $(\mu \mathrm{m})$ \\
\hline Ileum & $360 \pm 9(18)$ & $155 \pm 3(18)$ \\
lleal remnant & $651 \pm 14(28)^{*}$ & $207 \pm 5(28)^{*}$ \\
Jejunum & $506 \pm 15(17)$ & $146 \pm 4(17)$ \\
\hline
\end{tabular}

Mean values ( \pm SEM) of villus height and crypt depth in ileal remnants three weeks after $60 \%$ proximal small bowel resection are compared with those obtained from transected ilcum and jejunum. Numbers of rats are shown in parentheses. Values with an asterisk are significantly different from those found for control tissue $(\mathrm{p}<0 \cdot()) 1$ in cach case $)$.
The other was opened and mounted between two pieces of liver to be snap frozen in liquid $\mathrm{N}_{2}$-cooled isopentane for the cytochemical determination of aminopeptidase $\mathrm{N}$ and $\alpha$-glucosidase content .

\section{ANALYTICAL TECHNIQUES}

Aminopeptidase $\mathrm{N}$ activity (EC 3.4.11.2) was determined in $10 \mu \mathrm{m}$ sections of frozen tissue by incubation for $90 \mathrm{~s}$ at $\mathrm{pH} 6.5$ with $0.7 \mathrm{mM}$ L-alanine4 -methoxy- $\beta$-naphthylamide, after preliminary fixation for 10 minutes at $4^{\circ} \mathrm{C}$ in Baker's formal-calcium medium. Subsequent colour development, using Fast Blue $B$ reagent as coupler, was as described previously.' The total amount of enzyme reaction product formed was finally recorded by microdensitometry at a wavelength of $450 \mathrm{~nm}$.

$\alpha$-Glucosidase activity (a mixture of sucraseisomaltase EC 3.2.1.48-3.2.1.12; maltase EC 3.2.1.3 and trehalase EC 3.2.1.28) was determined in $10 \mu \mathrm{m}$ sections of frozen tissue by incubation for four minutes at $37^{\circ} \mathrm{C}$ with $12 \mathrm{mM}$ 2-naphthyl- $\alpha$-Dglucopyranoside, after preliminary fixation in Baker's formal-calcium medium for 10 minutes at $4^{\circ} \mathrm{C}$. Colour development with hexazonium-prosaniline was as described previously. ${ }^{13}$ Final estimates of the amount of enzyme reaction product present were carried out by microdensitometry at a wavelength of $530 \mathrm{~nm}$. All measurements of a $\alpha$ glucosidase and aminopeptidase $\mathrm{N}$ activities were carried out under initial rate conditions and were expressed in arbitrary absorbance units (au).

Scanning microdensitometry was carried out at a final magnification of $\times 1000$ using a Vickers M 85 microdensitometer (Vickers Instruments, York), sequential measurements of optical density being taken along the brush border membranes of enterocytes from crypt-villus junction to villus tip. Care was taken to avoid the inclusion of goblet cells in these measurements, their occasional presence being easily identified as a sudden and obvious discontinuity in the amount of enzyme reaction product. The dimensions of the scanning aperture used to measure aminopeptidase $\mathrm{N}$ were $22 \times 5 \mu \mathrm{m}$. This aperture width was extended to $12 \mu \mathrm{m}$ when measuring $\alpha$ glucosidase activity to enable a wider band of enzyme reaction product to be recorded. The final dimensions of the apertures chosen were sufficient to cover virtually all of the enzyme reaction product formed during incubation.

The increase in enzyme activities recorded on moving up the villus was computer-fitted by logistic growth curves having the form

$$
y=a+c /[1+\exp (-b(x-m))]
$$

where $a$ is the smallest amount of enzyme considered to be present in newly formed crypt enterocytes, $c$ is 
the predicted maximal enzyme activity found in midvillus enterocytes assuming $a$ equals zero, $m$ is the time when enterocyte enzyme activity increases at maximal rate and $b$ is the exponential coefficient of the change in activity related to enterocyte age. These curves were routinely fitted using the maximum likelihood program MLP (C) 1982, Lawes Agricultural Trust, Rothamsted Experimental Station). Additional comparisons were made between enzyme activities found in enterocytes at similar positions on the villus surface in different experimental situations. The significance of these differences was assessed by carrying out unpaired $t$ tests.

In order to relate measurements of enzyme activity to enterocyte age it was first necessary to calculate the rate at which enterocytes migrated along the cryptvillus axis. This objective was achieved by injecting tritiated thymidine $(1 \mu \mathrm{Ci} / \mathrm{g})$ intraperitoneally into rats which were then killed $2,10,20,30$, or 40 hours later. Pieces of intestine removed from these animals were processed for autoradiography as described previously. ${ }^{14}$ The leading edge of migrating thymidine labelled cells was finally measured in eosin stained autoradiographs using a curtain eye piece micrometer. Numerous parallel measurements of crypt depth and villus height were made on other sections of rat small intestine. Mean values obtained from these estimates were used to assess adaptation and site dependent differences in intestinal structure.

MATERIALS

[Methyl $-{ }^{-} \mathrm{H}$ ] thymidine $(5 \mathrm{Ci} / \mathrm{mmol})$ was purchased from Amersham International plc, Amersham, Bucks. The aminopeptidase $\mathrm{N}$ substrate L-alanine4-methoxy- $\beta$-naphthylamide came from the Sigma Chemical Company, Poole, Dorset and the $\alpha$-glucosidase substrate 2-naphtyl- $\alpha$-Dglucopyranoside from Koch-Light Laboratories, Colnbrook, Bucks. All other reagents used were of analytical reagent grade.

\section{Results}

\section{MORPHOMETRY}

Values for crypt depth and villus height, obtained from ileal remnant tissue three weeks after removal of $60 \%$ of the proximal small intestine, are compared with those obtained for transected ileum and jejunum in Table 1 . Resection increased ileal villus height by $81 \%$ and crypt depth by $34 \%$ compared with transection. Values for ileal remnants were $39-41 \%$ greater than those in transected jejunum. All of these differences were statistically significant $(\mathrm{p}<0 \cdot() 01)$.
EXPRESSION OF DIGESTIVE ENZYMES BY ILEAL ENTEROCYTES

Initial experiments were carried out to compare the profile for $\alpha$-glucosidase appearance in control ileal enterocytes with that determined in ileal remnant tissue three weeks after intestinal resection. Figure 1 shows that enterocytes migrating from the crypts of ileal remnant tissue already contained two to three times as much $\alpha$-glucosidase activity (a mixture of sucrase-isomaltase, maltase-glucoamylase and trehalase) as enterocytes migrating from the crypts of control tissues $(p<0 \cdot(0) 1)$. The activity of these enzymes then showed a three to four-fold increase as enterocytes continued to migrate over the first 250 $\mu \mathrm{m}$ of villus surface. After this there was a pronounced fall in $\alpha$-glucosidase activity in ileal remnant tissue during further enterocyte migration to the villus top. This fall was much less noticeable in control villus enterocytes, values at the respective villus tips being not statistically different.

The results obtained from a similar analysis of aminopeptidase $\mathrm{N}$ activities are shown in Figure 2. Aminopeptidase $\mathrm{N}$ activity in ileal enterocytes crossing the crypt villus junction was again higher after proximal enterectomy $(\mathrm{p}<0 \cdot 001)$, but this difference disappeared by the time enterocytes had migrated $250 \mu \mathrm{m}$ up the villus. The activity of aminopeptidase $\mathrm{N}$ then declined as enterocytes continued to migrate to the villus tip, activity at the tip again being indistinguishable from controls. Enzymatic adaptation to proximal enterectomy was generally much less marked for aminopeptidase $\mathrm{N}$ than $\alpha$-glucosidase.

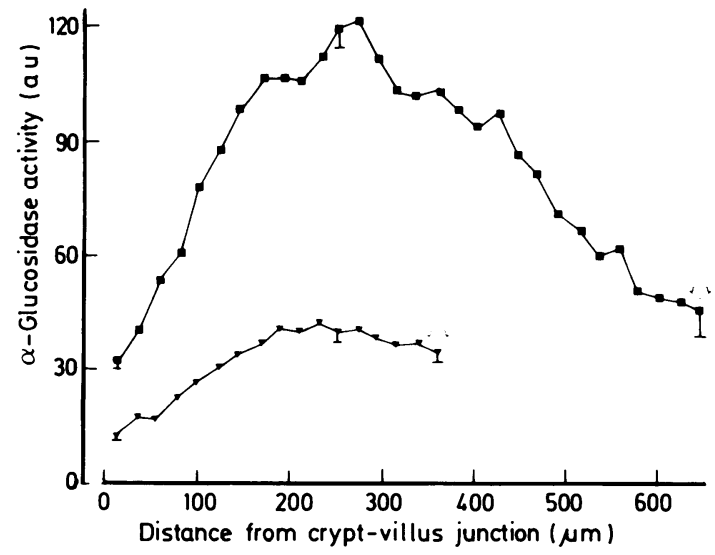

Fig. 1 Positional distribution of $\alpha$-glucosidase activity in ileal villus enterocytes three weeks after transection $(\nabla)$ or resection (ם) of proximal small bowel. Arrows mark the position of the villus tips. Each value gives the mean value in absorbance units ( $\pm S E M$ in selected cases) of estimates carried out on tissue taken from 18 control rats and 28 rats with resection (three villi per rat). 


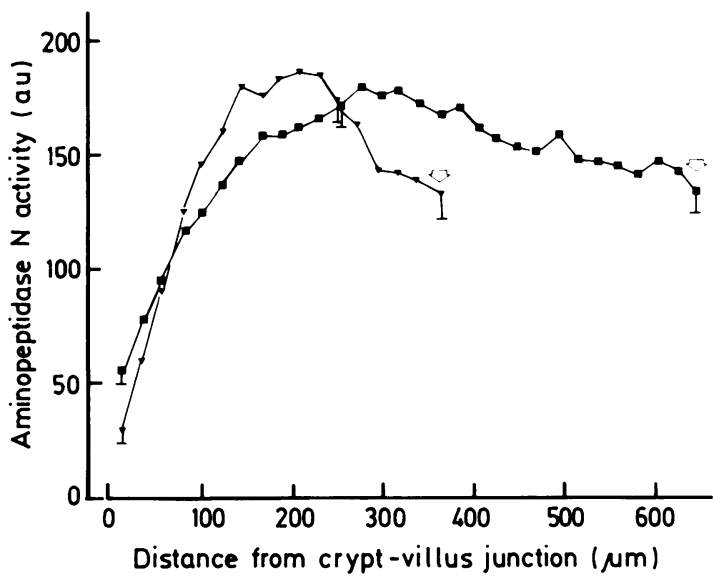

Fig. 2 Positional distribution of aminopeptidase $N$ activity in ileal villus enterocytes three weeks after transection ( $\nabla$ ) or resection ( $)$ of proximal small bowel. Arrows mark the position of the villus tips. Each value gives the mean value in absorbance units ( $\pm S E M$ in selected cases) of estimates carried out on tissue taken from 18 control rats and 28 rats with resection (three villi per rat).

\section{TEMPORAL ASPECTS OF ILEAL ENTEROCYTE} DEVELOPMENT

To relate developmental profiles for $\alpha$-glucosidase and aminopeptidase $\mathrm{N}$ to the actual age of the enterocytes, migration rates were first determined from thymidine-labelled autoradiographs. Enterocyte movement was linearly related to time after isotope injection in both control and ileal remnant tissue (correlation coefficients of 0.96 obtained from linear regression of measurements made in both tissues). Regression analysis of results obtained from rats killed approximately $2,10,20,30$, and 40 hours after thymidine injection gave calculated enterocyte migration rates of $11.1 \pm 1.0 \mu \mathrm{m} / \mathrm{h}$ in control ileum and $19.3 \pm 1.4 \mu \mathrm{m} / \mathrm{h}$ in ileal remnants. In relating enzyme profiles to enterocyte age (Fig. 3) attention has been confined to the rising phase of hydrolase expression during cell migration along the lower third of the villus. Logistic growth curves have also been fitted to this phase of enterocyte development to enable quantitative assessment of the various changes to be made.

Both aminopeptidase $\mathrm{N}$ and $\alpha$-glucosidase activities appeared earlier in enterocytes located in ileal remnant tissue, leading to about a four-fold increase in enzyme activity by the time enterocytes had become 10 hours old. The rate of appearance of aminopeptidase $\mathrm{N}$ during the next 10 hours was somewhat faster in control tissue, while the opposite was true for $\alpha$-glucosidase. The net result of these different effects was to produce 20 -h-old enterocytes having the same aminopeptidase $\mathrm{N}$ activity, but with

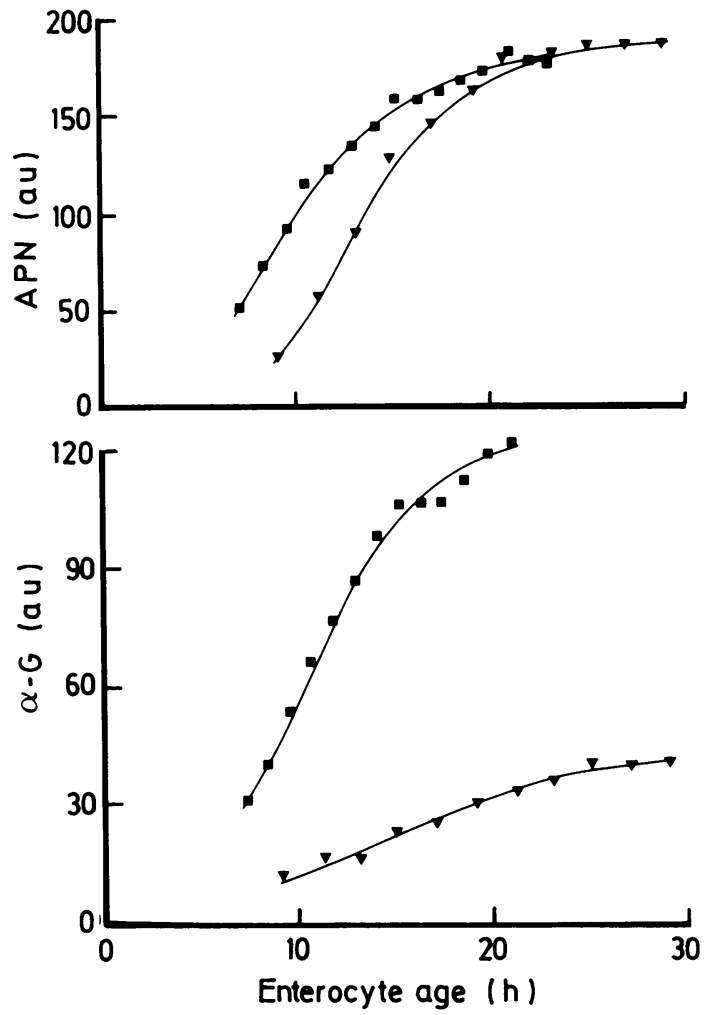

Fig. 3 Temporal aspects of $\alpha$-glucosidase $(\alpha-G)$ and aminopeptidase $N(A P N)$ appearance in ileal enterocytes. $V$ alues plotted for both enzymes in Figs 1 and 2 have been related to enterocyte age using migration rates of $11 \cdot 1 \pm 0 \cdot 1$ $\mu \mathrm{m} / \mathrm{h}$ (control tissue $\nabla$ ) and $19 \cdot 1 \pm 1.4 \mu \mathrm{m} / \mathrm{h}$ (hyperplastic tissue $\mathbf{0})$.

the activity of $\alpha$-glucosidase still some four-fold higher in ileal remnant tissue $(p<0 \cdot(001)$. The calculated maximal activities for aminopeptidase $\mathrm{N}$ (the $c$ values from logistic curve analysis) were $182.2 \pm 1.9$ au for control tissue and $174.8 \pm 2.8$ au for hyperplastic ileum. The corresponding values for $\alpha$ glucosidase were $49 \cdot 4 \pm 4 \cdot 9$ and $121 \cdot() \pm 2 \cdot 4 \mathrm{au}$.

EXPRESSION OF DIGESTIVE ENZYMES IN JEJUNAL ENTEROCYTES

$\alpha$-Glucosidase activity in enterocytes crossing the crypt villus junction in the jejunum was intermediate $(26 \cdot 1 \pm 3 \cdot 0 \mathrm{au})$ between values obtained for control ileum $(13 \cdot 1 \pm 2 \cdot 1 \mathrm{au})$ and ileum rendered hyperplastic by proximal small bowel resection $(32 \cdot 0 \pm 1 \cdot 2 \mathrm{au})$. Activity then increased until enterocytes became about 25 hours old (this time calculated from an estimated migration rate of $12 \cdot 7 \pm 0 \cdot 6 \mu \mathrm{m} / \mathrm{h}$ ). The corresponding maximal activity predicted from logistic curve analysis is $83 \cdot 3 \pm 2 \cdot 6$ au. This value 
again lies intermediate between those for control ileum (49.4 $\pm 4.9 \mathrm{au})$ and hyperplastic ileum $(121 \cdot 0 \pm 2 \cdot 4 \mathrm{au}) . \alpha$-Glucosidase activity finally fell as enterocytes continued to migrate to the villus tip, values at the villus tip $(43 \cdot 3 \pm 7 \cdot 2 \mathrm{au})$ being very similar to those found in the other two cases $(48 \cdot 5 \pm$ $7 \cdot 9$ and $38.5 \pm 5.2 \mathrm{au}$ ). These results confirm that $\alpha-$ glucosidase activity is higher in proximal than distal regions of the small intestine.

The pattern of aminopeptidase $\mathrm{N}$ appearance in transected jejunum was quite similar to that determined earlier for ileal tissues taken before and after intestinal resection. The predicted maximal activity found for jejunum $(212 \cdot 4 \pm 2 \cdot 1 \mathrm{au})$ was, however, slightly higher than that found both for control ileum $(182 \cdot 2 \pm 1 \cdot 9 \mathrm{au})$ and ileal remnant tissue $(174 \cdot 8 \pm 2 \cdot 7$ au).

\section{INTEGRATIVE ASPECTS OF ENTEROCYTE DEVELOPMENT}

The rates at which enzyme activities change have been plotted against enterocyte age in Figure 4 . The time taken to express $\alpha$-glucosidase activity at maximal rate decreased from 16 to 10 hours after intestinal resection. A similar but less pronounced change from 13 to 9 hours took place in the time taken to express aminopeptidase $\mathrm{N}$ activity at maximal rate. The corresponding times for maximal rates of $\alpha$-glucosidase and aminopeptidase $\mathrm{N}$ expression by jejunal enterocytes (12 and 11 hours) lie intermediate between those recorded for control ileum and ileal remnant tissue.

Absolute values for the maximal rate at which $\alpha$ glucosidase activity appears in rat brush border membranes showed a six-fold increase after resection. The corresponding values for aminopeptidase $\mathrm{N}$ activities showed a slight decrease. These results show quite clearly that it is change in the rate of $\alpha$ glucosidase expression rather than the reduction in time taken to express this enzyme at maximal rate which is of prime importance in determining the overall magnitude of the adaptive response to intestinal resection.

Previous measurements of villus height, width and thickness carried out on control ileum and ileal remnant tissue have shown the increase in villus surface area associated with proximal resection to be achieved by proportional enlargement of villus geometry. ${ }^{315}$ Knowing this, it is possible to calculate any other surface area from accurate measurement of villus height. Using the developmental profiles determined in the present work one can then calculate the total amount of aminopeptidase $\mathrm{N}$ and $\alpha$ glucosidase present on a single villus. The results of these calculations are summarised in Table 2.

The surface area of the jejunal villus and the

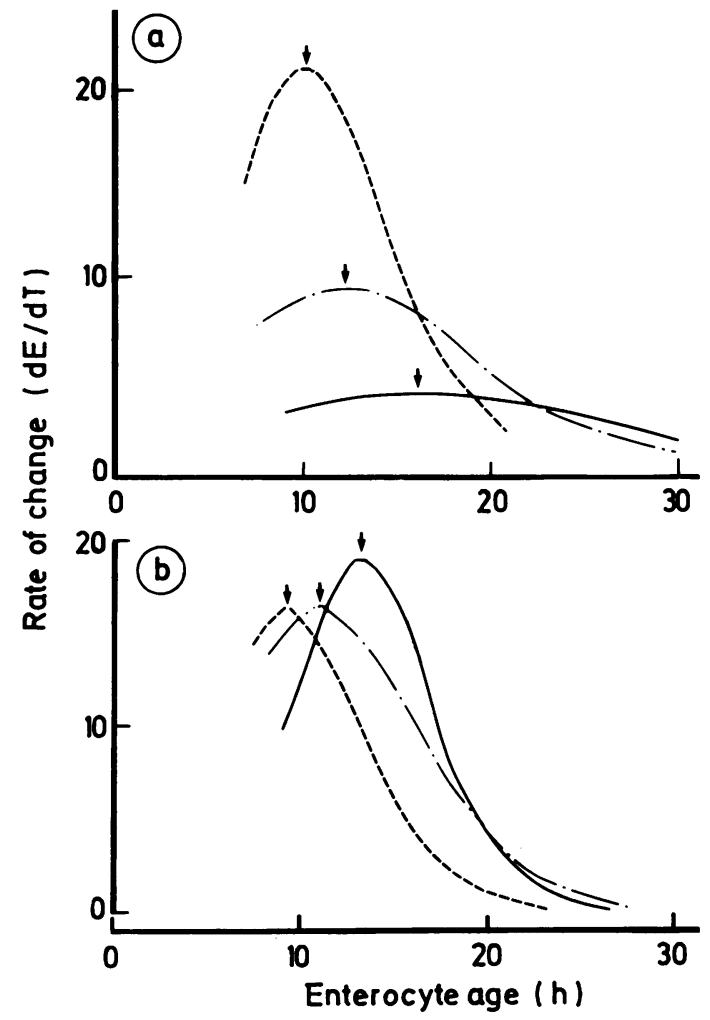

Fig. 4 Differential logistic growth curves describing $\alpha$ glucosidase and aminopeptidase $N$ appearance in rat enterocyte brush border membranes. Data obtained from control ileal (-), jejunal (- $(-)$ ) and hyperplastic ileal (.......) tissue have been plotted in differential form (rate of increase in enzyme activities, $d E / d T$ ) to show the rates at which $\alpha$-glucosidase (a) and aminopeptidase $N(b)$ activities change (absorbance units/h) during enterocyte development. Arrows show the calculated times for maximal rates of enzyme expression.

amount of aminopeptidase $\mathrm{N}$ it contained were approximately twice those of the control ileal villus. The surface area of the ileal remnant villus and the amount of aminopeptidase $\mathrm{N}$ activity it contained

Table 2 Villus surface area and total villus $\alpha$-glucosidase and aminopeptidase $N$ activities calculated for ileal remnant and for control ileal and jejunal tissue

\begin{tabular}{llll}
\hline $\begin{array}{l}\text { Measured } \\
\text { parameter }\end{array}$ & $\begin{array}{l}\text { Ileal } \\
\text { villus }\end{array}$ & $\begin{array}{l}\text { Jejunal } \\
\text { villus }\end{array}$ & $\begin{array}{l}\text { Ileal remnant } \\
\text { villus }\end{array}$ \\
\hline Area $\left(\mathrm{mm}^{2}\right)$ & $0 \cdot 32$ & 0.63 & $1 \cdot(04$ \\
Aminopeptidasc $\mathrm{N}\left(\mathrm{au} \times 10^{-6}\right)$ & $2 \cdot 47$ & 6.05 & $8 \cdot 10$ \\
$\alpha$-glucosidase $\left(\mathrm{au} \times 10^{-5}\right)$ & $0 \cdot 56$ & $2 \cdot 08$ & $4 \cdot 42$ \\
\hline
\end{tabular}

Results obtained by integrating values given in Figs 1 and 2 assuming villus geometry to be proportional to that described previously. ${ }^{3}$ 
were approximately equal to the sum of the values found for control ileal and jejunal villi. Adaptation in this case appears to be through a three-fold increase in surface area. The amount of $\alpha$-glucosidase activity found in the control jejunal villus was three to four times that found in the ileal villus. The ileal remnant villus contained 1.7 times the amount of enzyme found in control ileal plus jejunal tissue. Adaptation in this case occurs through an increase in surface area plus an obvious increase in the ability of individual ileal enterocytes to express this enzyme in their brush border membranes.

\section{Discussion}

Ileal villi adapt to a $60 \%$ proximal small bowel resection in the rat by a substantial increase in expression of $\alpha$-glucosidase but not neutral aminopeptidase enzymes. This finding seems to be at variance with earlier reports that the specific activities of maltase and sucrase determined in intestinal homogenates are either unchanged or diminished after resection ${ }^{n-x}$ and with the finding that purified preparations of ileal microvillar membranes obtained from dogs with proximal enterectomy show decreased activities of a wide range of digestive enzymes, including maltase, sucrase and aminopeptidase." Earlier cytochemical analysis of $\alpha$ glucosidase activity also shows slight inhibition in upper villus enterocytes, four and eight days after resection, although this effect has disappeared four days later. ${ }^{17}$ This variation in response to resection, which is not easily explained, could arise from variation in the relative position of the tissue taken for analysis and the site of resection or more probably because adaptation of tissue function takes longer to complete than does adaptation of intestinal structure.

Three weeks after jejunal resection ileal enterocytes can be seen to develop $\alpha$-glucosidase activity much more rapidly as they ascend the villus; at 20 hours they show four times the enzyme activity of control cells. In contrast, fluctuations in aminopeptidase expression are of much lesser degree, and by 20 hours activity has returned to control levels. This differential enzyme response recently shown between $\alpha$ - and $\beta$-glucosidases as well ${ }^{17}$ contradicts the suggestion of simple metabolic immaturity. Whereas increased peptidase activity after resection can be accounted for by increased surface area, increased disaccharidase activity also reflects the improved digestive function of individual enterocytes.

Among normal small bowel villi, jejunal activities of $\alpha$-glucosidase are four times as high as those in the ileum, while the difference is nearer two-fold for aminopeptidase. Our data thus confirm that disaccharidases are concentrated in the jejunum while peptidases are more evenly distributed along the small intestine. " "As jejunal resection preferentially depletes the gut of $\alpha$-glucosidase, an appropriate adaptive response, in addition to a general increase in villus surface area, might be anticipated in the ileum. Feeding rats on a high protein diet will increase the aminopeptidase activity of individual jejunal villi by increasing villus length. ${ }^{14}$ Presumably, therefore, the trigger to at least part of the postresectional increments in $\alpha$-glucosidase activity is the sudden exposure of the ileum to carbohydrates that were previously absorbed upstream. Like compensatory hyperplasia, the enzymic response of the distal small bowel would be the result of increased luminal (topical) nutrition, ${ }^{5}$ though tropic hormones such as enteroglucagon could help modulate structural and functional adaptation alike. ${ }^{2 \prime \prime}$

The morphometric changes observed in the ileum three weeks after $60 \%$ resection of the proximal small bowel confirm that compensatory hyperplasia is well established at this time. Normally ileal villi possess half the surface area of jejunal villi, but during adaptive growth their surface area increases three-fold. The magnitude of this increase more than compensates for a slight reduction in the number of cells per unit length of villus, so that the total population of villus enterocytes becomes larger. ${ }^{3}$ It must be remembered that all these changes apply to the intestine within a few centimetres of the anastomosis, where adaptation is maximal, and are less pronounced at further remove. ${ }^{13}$

After proximal small bowel resection enterocytes migrate along the ileal villi at nearly twice the normal rate. Although elongation of the villus ensures that they have a greater distance to travel, nevertheless it has been shown previously that they spend a shorter time on the villus. ${ }^{311}$ Moreover, expansion of the proliferative zone may reduce the time available for maturation in the upper third of the crypt. ${ }^{7}$ Thus a much more rapid development of brush border enzymes is necessary if cells are to maintain or even enhance their digestive function. For $\alpha$-glucosidase in particular, and aminopeptidase $\mathrm{N}$ to some extent, this rapid maturation is achieved by modification of the programme controlling enterocyte development. Qualitatively similar changes in the timing and rates at which enterocytes develop absorptive function have also been reported in rats after proximal resection of the small bowel."' It therefore seems that a number of common adaptive responses might be brought into play to counteract the effects of crypt hyperplasia, the extent of involvement being possibly dependent upon the strength of the applied stimulus. 
Part of this work was supported by a grant to MC from The British Council.

\section{References}

1 Williamson RCN. Intestinal adaptation. I. Structural, functional and cytokinetic changes. N Engl J Med 1978; 298: $1393-402$.

2 Williamson RCN. Intestinal adaptation: factors that influence morphology. Scand J Gastroenterol 1982; 17: suppl 74: 21-9.

3 Menge H, Hopert R, Alexopoulos T, Riecken EO. Three-dimensional structure and cell kinetics at different sites of rat intestinal remnants during the early adaptive response to resection. Res Exp Med (Berl) 1982; 181: 77-94.

4 Dowling RH, Booth CC. Functional compensation after small-bowel resection in man: demonstration by direct measurement. Lancet 1966; ii: 146-7.

5 Dowling $\mathrm{RH}$, Booth $\mathrm{CC}$. Structural and functional changes following small intestinal resection in the rat. Clin Sci 1967; 32: 139-49.

6 Bury KD. Carbohydrate digestion and absorption after massive resection of the small intestine. Surg Gynecol Obstet 1972; 135: 177-87.

7 Menge H, Robinson JWL. The relationship between the functional and structural alterations in the rat small intestine following proximal resection of varying extents. Res Exp Med (Berl) 1978; 173: 41-53.

8 Weser E. Hernandez MH. Studies of small bowel adaptation after intestinal resection in the rat. Gastroenterology 1971; 60: 69-75.

9 McCarthy DM, Kim YS. Changes in sucrase, enterokinase and peptide hydrolase after intestinal resection. The association of cellular hyperplasia and adaptation. J Clin Invest 1973; 52: 942-51.

10 Menge H, Sepulveda FV, Smith MW. Cellular adapta- tion of amino acid transport following intestinal resection in the rat. $J$ Physiol 1983; 334: 213-23.

11 Smith MW. Expression of digestive and absorptive function in differentiating enterocytes. Ann Rev Physiol 1985; 47: 247-60.

12 Nachlas MM, Crawford DT, Seligman AM. The histochemical demonstration of leucine aminopeptidase. J Histochem Cytochem 1957; 5: 264-78.

13 Gutschmidt S, Kaul W, Riecken EO. A quantitative histochemical technique for the characterisation of $\alpha$ glucosidases in the brush-border membrane of rat jejunum. Histochemistry 1979; 63: 81-101.

14 King IS, Paterson JYF, Peacock MA, Smith MW, Syme G. Effect of diet upon enterocyte differentiation in the rat jejunum. J Physiol (Lond) 1983; 344: 465-81.

15 Robinson JWL, Van Melle G, Riecken EO, Menge $H$. Structural and functional correlations in the hypertrophic mucosa of intestinal remnants following resection in rats. Res Exp Med 1982; 181: 95-104.

16 Fehlmann M, Starita- Geribaldi M, Thiebaut C, Sudaka P. Effect of massive small bowel resection on intestinal brush border membrane proteins in the dog. Arch Int Physiol Biochim 1978; 86: 601-12.

17 Gutschmidt S, Kaul W, Menge H, Riecken EO. The adaptive response of disaccharidase activities at different sites along the villus epithelium after proximal intestinal resection in the rat. A microdensitometric study of enzyme kinetics. Res Exp Med (Berl) 1983; 182: 203-13.

18 Espinoza J, Rosenweig NS, Hritz A. Distribution and adaptive response of rat intestinal glycolytic enzymes. Gastroenterology 1972; 62: 844.

19 Triadou N, Battaille J, Schmitz J. Longitudinal study of the human intestinal brush border membrane proteins. Distribution of the main disaccharidases and peptidases. Gastroenterology 1983; 85: 1326-32.

20 Dowling RH. Small bowel adaptation and its regulation. Scand J Gastroenterol 1982; 17: suppl 74: 53-74. 